\title{
A CASE OF LISTERIA MONOCYTOGENES MENINGITIS IN AN IMMUNOCOMPETENT 16-MONTH-OLD CHILD.
}

\section{Bosis $S^{1}$, Castellazzi ML2 , Pinzani R1, Tagliabue $C^{1}$, Marchisio P1 $^{1}$}

1Pediatric Highly Intensive Care Unit, Department of Pathophysiology and Transplantation, Università degli Studi di Milano,

Fondazione IRCCS $\mathrm{Ca}^{\prime}$ Granda Ospedale Maggiore Policlinico, Milan, Italy

2 Cystic Fibrosis Centre, Fondazione IRCCS Cà Granda Ospedale Maggiore Policlinico, Milan, Italy

\section{BACKGROUND}

Listeria monocytogenes (LM) is a gram-positive bacteria transmitted to humans through ingestion of contaminated food. It causes severe infections in immunocompromised patients, but it is rarely reported in previously healthy and immunocompetent subjects.

\section{CASE REPORT}

A previously healthy, immunocompetent, 16-month-old girl was hospitalized for high grade fever, vomiting and irritability. On admission, the patient was in good clinical conditions and the clinical examination was normal with no sign of meningitis. Laboratory tests showed white blood cell (WBC) counts of $14090 / \mathrm{mmc}$ ( $75.7 \%$ neutrophils) and C-reactive protein (CRP) of $5.76 \mathrm{mg} / \mathrm{dl}$ (normal value $<0.5 \mathrm{mg} / \mathrm{dl}$ ); renal and liver function and coagulation tests were within the normal range. Intravenous ceftriaxone was started. The patient's clinical and neurological conditions rapidly worsened. The computed tomography (CT) scan of the brain was normal. A lumbar puncture was performed and cerebrospinal fluid (CSF) analysis revealed 840 cells/mmc with neutrophilic predominance, glucose and protein concentration of 38 and $44 \mathrm{mg} / \mathrm{dl}$ respectively. The real-time polymerase chain reaction (RT-PCR) for bacteria and the culture of CSF were positive for LM Ceftriaxone was discontinued and intravenous ampicillin plus gentamicin were started and continued for a total 21 days. A brain magnetic resonance imaging scan showed mild meningeal enhancement without parenchyma involvement (Fig. 1,2). The patient improved rapidly and she was discharge after 22 days. She had not any neurological seguelae.
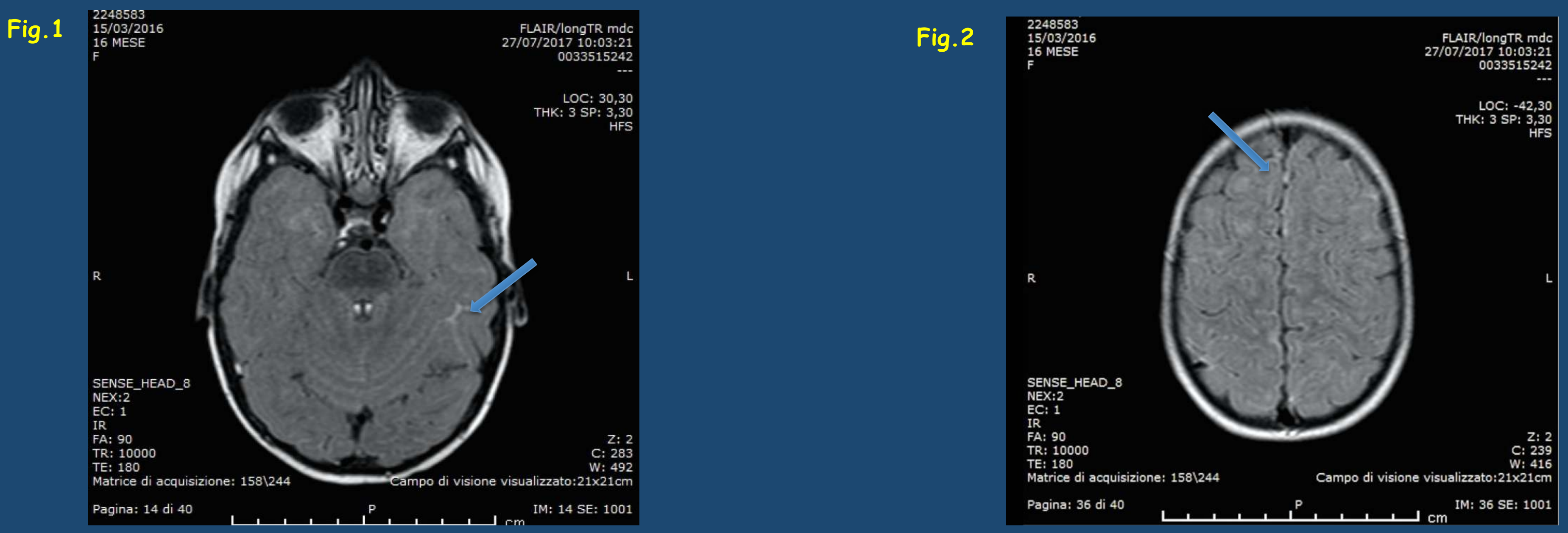

\section{CONCLUSIONS}

LM represents a rare cause of meningoencephalitis in previously healthy and immunocompetent children, but it could progress rapidly and may be associated with severe complications and a high mortality rate. Prompt diagnosis is essential to start adequate antibiotic treatment. 